\title{
Milling and Physical Characteristics of Pigmented Rice Varieties
}

\author{
Saravanan Ponnappan, Arun Thangavel, Omprakash Sahu \\ Faculty of Chemical and Food Engineering, BiT, Bahir Dar University, Bahir Dar, Ethiopia
}

Email address:

ops0121@gmail.com (O.Sahu)

\section{To cite this article:}

Saravanan Ponnappan, Arun Thangavel, Omprakash Sahu. Milling and Physical Characteristics of Pigmented Rice Varieties. Journal of Food and Nutrition Sciences. Vol. 5, No. 6, 2017, pp. 236-241. doi: 10.11648/j.jfns.20170506.15

Received: May 11, 2017; Accepted: July 27, 2017; Published: November 30, 2017

\begin{abstract}
In the present study, four different pigmented rice varieties, namely glutinous white rice, black rice and two red rice varieties (TPS-1 and TKM-9) were evaluated for various quality aspects in terms of milling and physical characteristics such as hulling percentage, milling percentage, whole kernel recovery, milling loss, thousand grain weight, grain volume, bulk density, true density, grain length, grain width and L/B ratio. Among the four rice varieties TPS-1 had the highest hulling percentage, milling percentage, whole kernel recovery percentage. While as, glutinous white rice had the lowest milling loss. Thousand grain weight, grain volume was higher in glutinous white rice variety. Bulk density and true density were found to be highest for glutinous white rice followed by TPS-1, TKM-9 and black rice. Milling characteristic in terms of hulling percentage, milling percentage, whole kernel recovery and milling loss showed significant difference between the varieties. L/B ratio was found to be highest for glutinous white rice followed by TPS-1, TKM- 9 and black rice variety. Grain length and grain width observed range from $5.38-6.38 \mathrm{~mm}$ and $1.90-2.24 \mathrm{~mm}$.
\end{abstract}

Keywords: Milling Characteristic, Whole kernel Recovery, L/B Ratio, Bulk Density

\section{Introduction}

Rice is important cereal crop in Asia, Africa and the staple food for many developing countries (Osawa et al., 1992). The common rice colored by man in white rice (about $85 \%$ ) followed by brown colour rice and the rest in pigmented rice. The colored rice is essentially red, black and purple colour rice, which have dark red, dark purple, dark blue, light purple grain (Asamarai et al., 1996).

Screening of rice varieties for physicochemical characteristics is necessary for quality evaluation and possible food industry applications. Ghrist (1965) and Anon (1996) reported that the utilization of rice for food purpose involves milling of paddy to remove the husk, bran and germ from the surface of the grain. Milling of rice has intensive effect on its nutrient composition. Losses of nutrient, resulting from milling and polishing of rice, vary considerably depending on the number of layers removed during processing and on the inherent varietal quality. Enormous variation in size and the shape of grain exists among the rice varieties (Murthy and Govindaswamy, 1967). Rice kernel length roughly varies from 5.0-7.5 mm and breadth from 1.9-3.0 mm. Some high yielding varieties from India vary between $5.2-6.8 \mathrm{~mm}$ in length and 1.9-2.5 $\mathrm{mm}$ in breadth (Nanda et al., 1976). Japonica varieties are generally shorter and bolder grains. Generally, hulling out turn is reported to be in the range of 7183 per cent. The forming variation within cultivated on Indian varieties in respect to hulling percentage is noticed to be little, but high in Taiwan and Japanese varieties. Many Japonica rice varieties give hulling out turns of over 79 per cent (Govindaswamy et al., 1969).

According to Ramiah (1993) there are about eleven different colour rice varieties, varying from white (most common), to various shades of red to purple (almost black). Rice with kernel colors of gold, deep brown or grey are also present. Bandyopadhyay and Roy (1992) observed that the milling quality or milling yield of paddy is affected by variety, moisture content, pretreatments such as parboiling and processing (milling) equipments and methods. Ganesanet al., (1998) reported that 1000 grain weight of rice varied from 15.76 to $29.24 \mathrm{~g}$. The researcher also reported a moderate correlation between length of grain and grain weight. But Riccharia and Govindaswami (1990) found that the 1000 grain width of rice ranged from 12.0 to $47.5 \mathrm{~g}$. 
Siebenmorganet al, (1998) observed that when the milled long grains were exposed to varying air temperatures, kernels were discussed to a breakage list, to determine the extent of physical damage that persist during each and every exposure situation. Usually, milled rice was higher content in moisture and also excess extensive stress and crack damage. Kernel appearance, shape, size, nutritional value and other cooking parameters are reported to be essential for assessing the quality of rice from one group of consumers to another (Cruz and Khush, 2000). Gupta and Agarwal (2000) opined that the morphological traits like grain length, L/B ratio, grain size etc. appeared to be quite stable and could therefore, be used as primary diagnostic characters for classifying paddy varieties. According to Nirmala (1997) thousand grainweight is suggested to be related to kernel sizes and its density, and this determinant is often an indication of milling quality.

There is considerable variation in rice grain size ranging from long bold to short bold (CRRI, 1999). In rice varieties, length of unhulled grain ranged from under $5 \mathrm{~mm}$ to over 14 $\mathrm{mm}$. The range in breath was from 1.9 to $3.7 \mathrm{~mm}$ and the thickness ranged from 1.5 to $2.2 \mathrm{~mm}$. Reddy (2000) observed that the mean grain length of medicinal rice variety, Njavara (red coloured rice) ranged from $7.6 \mathrm{~mm}$ to $9.3 \mathrm{~mm}$ and also breadhranged from $2.65 \mathrm{~mm}$ to $3.33 \mathrm{~mm}$.

\section{Materials and Methods}

\subsection{Sample Collection}

To study the sample experimental pigmented paddy rice
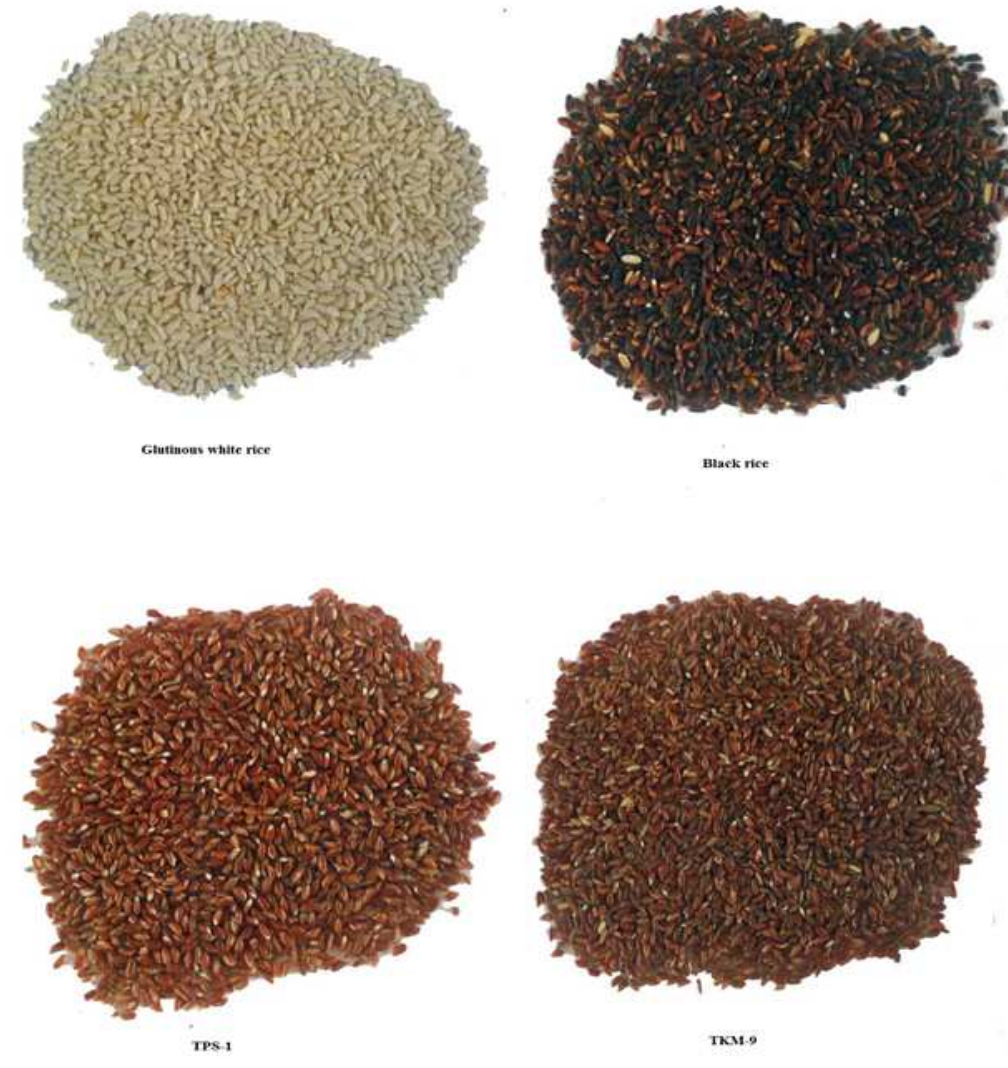

Figure 1. Different rice varieties used on experimental work.

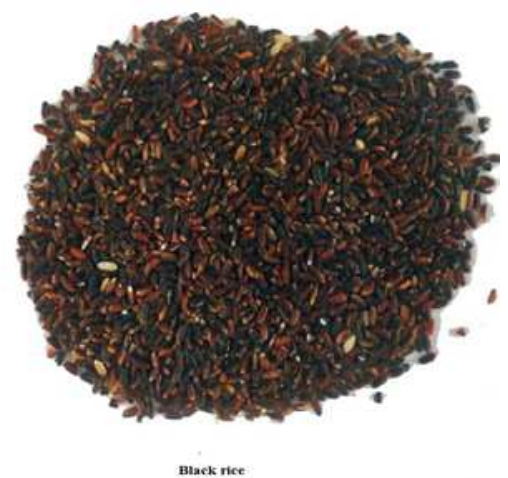

varieties (plate-1) were selected and purchased from various available markets in India. The paddy of black rice (kavuni rice) was obtained from Dry Land Agriculture Research Station, Kanadukathan, Chettinad, India. Red rice paddy varieties TPS-1 were obtained from Regional Rice Research Station, Thirupathisaram and TKM-9 obtained from Rice Research Station, Thirurkuppam, Thiruvallur. Glutinous white rice which was sourced from Mumbai was purchased from Remuki Departmental stores, Madurai, India.

Milling Characteristics

The milling characteristics were computed as per the methods given by Ghosh et al. (1971) for rice.

Hulling percentage

One hundred gram sample of dried (11-13\% moisture) paddy grain samples were dehulled in Satake Dehusker and the weight of the dehusked kernels were recorded. Hulling percentage was computed as:

$$
\text { Hullingpercentage }=\frac{\text { Weight of dehusked kernels }}{\text { weight of grains }} \times 100
$$

\section{Milling percentage}

Dehusked samples of the selected rice varieties were polished using a Satake Grain Testing Mill for 30 seconds. This was followed by a second milling for another 30 seconds to obtain the polish and the total weight of polished kernels was recorded. Milling percentage was calculated as:

$$
\text { Milling percentage }=\frac{\text { weight of milled kernels }}{\text { weight of grains }} \times 100
$$




\subsection{Whole Kernel Recovery Percentage}

The milled samples were sieved in a series of screens to separate head rice, brokens and bran. Small portion of whole kernels that passed along with brokens through the sieves were culled out from the milled samples. Full kernels and three fourth kernels were taken as whole milled kernels for computation. The whole kernel recovery percentage was calculated as:

$$
\begin{aligned}
& \text { Wholekernelrecoverypercentage } \\
& \qquad=\frac{\text { weight of whole milled kernels }}{\text { weight of grains }} \times 100
\end{aligned}
$$

\subsection{Milling Loss}

Milling loss was calculated from hull per cent, bran per cent and for unit of rice expressed in percentage (Adair, 1952).

\subsection{Physical Characteristics}

The nutraceutical components present in the rice bran of the pigmented rice varieties have been reported to mainly contribute to the health benefits of black and red rice varieties. Hence, further study was carried out using the dehulled rice kernels which were not subjected to milling process to remove the nutrient rich bran. The procedures followed for assessing the physical characteristics of the dehulled rice kernels of the selected rice varieties is detailed below.

\subsection{Thousand Grain Weight}

The thousand grain weight was measured by the method of Elsy et al., (1992). It involved the counting and weighing of 1000 randomly selected unpolished black rice, red rice and white rice kernels.

\subsection{Grain Volume}

Grain volume was measured as described by Ali et al., (1993). A $500 \mathrm{ml}$ graduated cylinder was filled with a known amount of water $(100 \mathrm{ml})$. Thousand grains of milled rice kernels were dropped into the cylinder with water. Tapped the cylinder to remove any air bubbles attached to the rice grains and recorded the total volume (rice + water). Subtracted the initial volume of water from this to get the grain volume and expressed as $\mathrm{mm}^{-1}$.

\subsection{Bulk Density}

Bulk density was the ratio of the mass to the volume of the sample or mass per unit volume, expressed as $\mathrm{g} / \mathrm{ml}$ or $\mathrm{kg} / \mathrm{L}$. Bulk density was used as an index for comparing the volume of different foods. The sample was taken to a height of $20 \mathrm{~cm}$ in a $50 \mathrm{ml}$ beaker. It was levelled without compressing. The weight of the sample with the beaker and water was filled to the same level $(20 \mathrm{ml})$. The weight of the sample with beaker was recorded and calculated using the formula

$$
\text { Bulk density }=\frac{\text { weight of the sample }}{\text { weight of the equivalent volume of water }}
$$

\subsection{True Density}

True density was the ratio of the mass to the volume of the sample or mass per unit volume, expressed as $\mathrm{g} / \mathrm{ml}$ or $\mathrm{kg} / \mathrm{L}$. True density was used as an index for comparing the volume of different foods. The sample was taken to a height of $20 \mathrm{~cm}$ in a $50 \mathrm{ml}$ beaker. It was levelled without compressing. The weight of the sample with the beaker and oil was filled to the same level $(20 \mathrm{ml})$. The weight of the sample with beaker was recorded and calculated using the formula.

$$
\text { True density }=\frac{\text { weight of the sample }}{\text { weight of the equivalent volume of oil }}
$$

\subsection{Grain Shape and Appearance}

The appearance of milled rice is important to consumers. Grain appearance depends upon the shape of kernel and hence, length, width, and appearance of grains were evaluated. Grain length and width were measured as suggested by Kaul (1970). About 50 rice grains were arranged linearly on a laboratory table lined with graph paper to measure the length and then took the average value. Width was measured by stacking 50 grains on top of one another on the graph paper and the average value was noted. Grain length and width were expressed in $\mathrm{mm}$.

\section{Result and Discussion}

\subsection{Milling Characteristics of Paddy Grains of Selected Rice Varieties}

The milling characteristics of the selected rice varieties were evaluated and the related data in presented in Table 1.

The hulling percentage was maximum in the TPS- 1 red rice variety $(76.52 \%)$ followed by black rice (74.29), glutinous white rice $(72.36 \%)$ and minimum in red rice TKM-9 (71.44\%). The milling percentage also followed the same trend, with maximum values seen in TPS-1 (66.21\%) compared to $62.64,62.51$ and 58.28 in black rice, white rice and TKM-9 respectively. The whole kernel recovery was high in TPS-1 which was recorded as 60.18 per cent followed by black rice $(57.34 \%)$. The milling loss was minimum in glutinous white rice which recorded a milling loss of 9.81 per cent compared to $11.65,10.31$ and 13.16 per cent noticed in black rice, TPS-1 and TKM-9 respectively. Results showed that the selected rice varieties exhibited significant differences in milling loss between white glutinous rice, black rice, TPS-1 andTKM-9.

Pandey and Gupta (2000) observed the milling characteristics of eighteen varieties of paddy grown in India. The brown rice yield varied from 75.1 per cent to 79.60 per cent, whereas, the milling yield ranged from 67.01 per cent to 
75.45 per cent at a constant time of polishing.

Ravindra et al., (2009) reported the head rice yield of brown rice to range from 67.0 to 73.0 per cent and from 48.7 to 67.9 per cent after polishing. The mean milling efficiency values varied from 44.8-57.8 per cent respectively.

\subsection{Physical Characteristics of the Selected Rice Varieties}

The physical characteristics of the selected rice varieties were assessed for thousand grain weight, volume, bulk density, true density, grain shape and appearance (grain length, grain width, $\mathrm{L} / \mathrm{B}$ ratio).

\subsection{Thousand Grain Weight, Grain Volume and Bulk Density}

Data pertaining to the 1000 grain weight, volume, bulk density and true density of selected rice varieties is depicted in Table 2. The 1000 grain weight was maximum in glutinous white rice $(22.25 \mathrm{~g})$ followed by TPS-1 (20.80g), TKM-9 (19.82) and black rice (17.50g). The grain volume of selected pigmented rice varieties showed variation as $2.52 \mathrm{~mm}^{3}$ (glutinous white rice), $2.31 \mathrm{~mm}^{3}$ (TPS-1), $2.14 \mathrm{~mm}^{3}$ (TKM-9) and $2.12 \mathrm{~mm}^{3}$ (black rice). Least 1000 grain weight and volume was obtained for black rice.

Table 1. Milling characteristics (\%) of selected rice varieties

\begin{tabular}{lllll}
\hline Varieties & Hulling & Milling & $\begin{array}{l}\text { Whole } \\
\text { kernel }\end{array}$ & Milling loss \\
\hline & percentage & percentage & recovery (\%) & $\mathbf{( \% )}$ \\
\hline Glutinous & $72.36 \pm 0.05$ & $62.51 \pm 0.05$ & $56.42 \pm 0.07$ & $9.81 \pm 0.05$ \\
white rice & & $62.64 \pm 0.05$ & $57.34 \pm 0.04$ & $11.65 \pm 0.06$ \\
Black rice & $74.29 \pm 0.06$ & $66.21 \pm 0.04$ & $60.18 \pm 0.08$ & $10.31 \pm 0.04$ \\
TPS-1 & $76.52 \pm 0.07$ & $58.28 \pm 0.07$ & $52.43 \pm 0.05$ & $13.16 \pm 0.05$ \\
TKM-9 & $71.44 \pm 0.04$ & 5.0110 & 0.0168 & 0.0062 \\
SEd & 0.0093 & $0.0268^{* *}$ & $0.0412^{* *}$ & $0.0153^{* *}$ \\
CD $(0.05)$ & $0.0228^{* *}$ & & & \\
\hline
\end{tabular}

Table 2. Thousand grain weight, grain volume and bulk density of the selected rice varieties.

\begin{tabular}{lllll}
\hline Varieties & $\begin{array}{l}\text { Thousand } \\
\text { grain weight } \\
(\mathbf{g})\end{array}$ & $\begin{array}{l}\text { Grain } \\
\text { volume } \\
\left(\mathbf{m m}^{\mathbf{3}}\right)\end{array}$ & $\begin{array}{l}\text { Bulk } \\
\text { density(g/ml) }\end{array}$ & $\begin{array}{l}\text { True } \\
\text { density } \\
(\mathbf{g} / \mathbf{m l})\end{array}$ \\
\hline Glutinous & $22.52 \pm 0.07$ & $2.52 \pm 0.02$ & $1.12 \pm 0.04$ & $2.27 \pm 0.01$ \\
white Rice & & & & \\
Black rice & $17.50 \pm 0.04$ & $2.12 \pm 0.03$ & $0.96 \pm 0.01$ & $1.92 \pm 0.03$ \\
TPS-1 & $20.80 \pm 0.03$ & $2.31 \pm 0.03$ & $1.01 \pm 0.02$ & $2.08 \pm 0.02$ \\
TKM-9 & $19.82 \pm 0.04$ & $2.14 \pm 0.03$ & $0.98 \pm 0.04$ & $1.95 \pm 0.02$ \\
SEd & 0.0162 & 0.0176 & 0.0160 & 0.0105 \\
CD $(0.05)$ & $0.0395 * *$ & $0.0430^{* *}$ & $0.0393 * *$ & $0.0256^{* *}$ \\
\hline
\end{tabular}

Results showed that the selected varieties exhibited significant difference $(\mathrm{P}<0.005)$ in the grain volume as seen between varieties glutinous white rice, black rice, TPS-1 and TKM-9.

The bulk density of the rice varieties ranged from 0.96 to $1.12 \mathrm{~g} / \mathrm{ml}$ with minimum and maximum values observed in black rice and glutinous white rice respectively. The true density of rice varieties ranged from 2.27 (glutinous white rice) to $1.92 \mathrm{~g} / \mathrm{ml}$ (black rice). Significant difference between the selected rice varieties was observed for the physical parameters studied.
Medicinal red rice, the Njavara variety was reported by Elsy et al., (1992) to have mean 1000 grain weight of $20.1 \mathrm{~g}$, and to range between $18.5 \mathrm{~g}$ to $30.0 \mathrm{~g}$ as given by Reddy (2000). Prashant et al., (2012) on observation of the physical properties of PR-106 type of rice variety under processing operation, reported that the grain volume of kernels ranged from 0.050 to $0.054 \mathrm{ml}$ with mean value of $0.051 \pm 0.002 \mathrm{ml}$. The true density value was within 1.517 to $1.528 \mathrm{~g} / \mathrm{ml}$.

Among six different rice varieties evaluated by Thomas et al., (2013) for physiochemical properties, the thousand kernel weight varied between 16.97-19.43 g, while the bulk density varied between $0.81-0.86 \mathrm{~g} / \mathrm{ml}$.

\subsection{Grain Shape and Appearance}

The grain shape was determined on the basis of the length to breadth ratio of the milled rice samples, while the grain appearance was ascertained on the basis of the kernel size, translucency and chalkiness of the rice kernels. The $\mathrm{L} / \mathrm{B}$ ratio of above 3 is generally considered as slender (IRRI, 1980).

Data related to the grain shape and appearance for selected rice varieties are given in Table 3. The $\mathrm{L} / \mathrm{B}$ ratio varied from 2.84 (glutinous white rice) to 2.61 (black rice), with TPS-1 and TKM-9 having values of 2.70 and 2.67 respectively. Among six rice varieties evaluated by Thomas et al., (2013) for physiochemical properties, the highest $\mathrm{L} / \mathrm{B}$ ratio was recorded for white rice (3.75), whereas, the lowest ratio was recorded for brown rice (2.09), which is in conformation to the results obtained in the present study.

Based on the interpretation of the selected rice varieties for shape, it was revealed as long and slender (black rice), slender and medium (TPS-1 and TKM-9) and also short and slender (glutinous white rice). Significant difference was noticed between the selected rice varieties in terms of grain shape. According to length, the grains are classified as very long (more than $7.5 \mathrm{~mm}$, long (6.61 to $7.50 \mathrm{~mm}$ ), medium or intermediate $(5.51$ to $5.60 \mathrm{~mm}$ ) and short (less than $5.50 \mathrm{~mm}$ ). Twenty four indigenous aromatic cultivars were analyzed for their grain characteristics and physico-chemical quality attributes by Srivastava and Jaiswal (2013). The kernel length ranged from 3.33 to $5.76 \mathrm{~mm}$ for short grain type, 6.34 to $8.02 \mathrm{~mm}$ for long grained basmati types and 4.65 to $6.34 \mathrm{~mm}$ among non-aromatic genotypes. Based on the L/B (before cooking), the short grain types were classified as either short bold or medium slender types. The basmati types were long slender or extra long slender while non-aromatic types were short slender, medium slender or long slender.

Table 3. Grain shape and appearance of the selected rice varieties.

\begin{tabular}{|c|c|c|c|c|}
\hline Varieties & $\begin{array}{l}\text { Grain } \\
\text { Length } \\
(\mathrm{mm})\end{array}$ & $\begin{array}{l}\text { Grain } \\
\text { Width(mm) }\end{array}$ & $\mathrm{L} / \mathrm{B}$ ratio & Interpretation \\
\hline $\begin{array}{l}\text { Glutinous } \\
\text { white Rice }\end{array}$ & 6.38 & 2.24 & $2.84 \pm 0.05$ & Short and slender \\
\hline Black rice & 5.62 & 2.15 & $2.61 \pm 0.04$ & Long and slender \\
\hline TPS-1 & 5.13 & 1.90 & $2.70 \pm 0.03$ & Slender and medium \\
\hline TKM-9 & 5.38 & 2.01 & $2.67 \pm 0.03$ & Slender and Medium \\
\hline SEd & & & 0.0152 & \\
\hline $\mathrm{CD}(0.05)$ & & & $0.0372 * *$ & \\
\hline
\end{tabular}


Chalkiness of rice varieties was observed to be maximum in glutinous white rice compared to the other varieties. Breakage of the dorsal ventral end of the grain ranged in intensity from black rice and followed by TKM-9, TPS-1 and glutinous white rice.

\section{Conclusion}

The selected pigmented rice varieties (viz., black rice of Chettinadu origin, red rice varieties TPS- 1 and TKM-9 and glutinous white rice (serving as the control) were evaluated for their milling characteristics. The hulling percentage was maximum in the TPS-1 red rice variety $(76.52 \%)$ followed by black rice $(74.29)$, glutinous white rice $(72.36 \%)$ and minimum in red rice TKM-9 (71.44\%). The milling percentage also followed the same trend, with maximum values seen in TPS-1 (66.21\%) compared to 62.64, 62.51 and 58.28 in black rice, white rice and TKM-9 respectively. The whole kernel recovery was high in TPS-1 which was recorded as 60.18 per cent followed by black rice $(57.34 \%)$. The milling loss was minimum in glutinous white rice which recorded a milling loss of 9.81 per cent compared to 11.65 , 10.31 and 13.16 per cent noticed in black rice, TPS-1 and TKM-9 respectively. The 1000 grain weight was maximum in glutinous white rice (22.25g) followed by TPS-1 (20.80g), TKM-9 (19.82) and black rice $(17.50 \mathrm{~g})$. The grain volume of selected pigmented rice varieties showed variation as $2.52 \mathrm{~mm}^{3}$ (glutinous white rice), $2.31 \mathrm{~mm}^{3}$ (TPS-1), $2.14 \mathrm{~mm}^{3}$ (TKM-9) and $2.12 \mathrm{~mm}^{3}$ (black rice). Least 1000 grain weight and volume was obtained for black rice. The bulk density of the rice varieties ranged from 0.96 to $1.12 \mathrm{~g} / \mathrm{ml}$ with minimum and maximum values observed in black rice and glutinous white rice respectively. The true density of rice varieties ranged from 2.27 (glutinous white rice) to 1.92 (black rice). The $\mathrm{L} / \mathrm{B}$ ratio varied from 2.84 (glutinous white rice) to 2.61 (black rice) and black rice was found to be long and slender compared to the red rice (TPS-1 and TKM-9) which were slender and medium and glutinous white rice as short and slender. Chalkiness of rice varieties was observed to be maximum in glutinous white rice compared to the other varieties.

\section{References}

[1] Adair, C. R. 1952. The McGill Miller method for determining the milling quality of small samples of rice. Rice Journal. 55 (2): 21 .

[2] Ali, L. C., Pan, J. and Dan, B. W. 1993. The mineral nutrient component and characteristics of color and white brown rice. Chinese Journal of Rice Science. 7(2): 95-100.

[3] Anon. 1996. The wealth of India, Raw Materials. Publication and Information Directorate, CSIR, New Delhi. (7): 164-183.

[4] Asamarai, A. M., Addis, P. B., Epley, R. J., and Krick, T. P. 1996. Wild rice hull antioxidants. Journal of Agricultural and Food Chemistry. 44: 126-130.
[5] Bandyopadhyay, S. and Roy, N. C. 1992. Rice Process Technology. Oxford and IBH Publishing co. pvt. ltd. New Delhi. 35-99.

[6] CRRI. 1999. Annual report for 1999. Central Rice Research Institute, Cuttack. Pp. 40.

[7] Cruz Dela, N. and Khush, G. S. 2000. Rice grain quality evaluation procedures. In: Aromatic rices. Singh RK, Singh, US, Khush GS, (Eds). Oxford and IBH Publishing Co. Pvt. Ltd., New Delhi, India. Pp. 16-28.

[8] Elsy, C. R., Roasamma, C. A., and Potty, N. N. 1992. Njavara - a rice variety with special characters. Oryza. 29: 55-56.

[9] Ganesan, S. P., Sivasubramaniam., Swaminathan, R and Srinivasan, V. 1998. Grain weight in cultivated strains of paddy, Madras Agricultural Journal. 5: 256-259.

[10] Ghosh, A. K., Nanda, B. B., Swami, S. G and Nayak, B. B. 1971. Influence of nitrogen on the physico-chemical characteristics of rice grain. Oryza. 891: 87-97.

[11] Ghrist, J. 1965. Influence of nitrogen on the physico-chemical characteristics of rice grain. Oryza. 891: 87-97.

[12] Govindaswami, S., Ghosh, A. K., Nanda, B. B. 1969. Varietal differences in hulling and cookingqualities. Annual Report of Central Rice Research Institute India.

[13] Gupta, P. K. and Agarwal, R. L. 2000. Determination of varietal purity of paddy varieties by laboratory evaluation. Oryza. 25: 310-314.

[14] IRRI International Rice Research Institute. 1980. Annual report for 1980. Los Banos, Laguna, Philippines. Pp 25-38.

[15] Kaul, A. K. 1970. Earlier generation testing for quality characters II, Rice. Indian Journal of Genetics and Plant Breeding. 303: 237-243.

[16] Murthy, P. S. N. and Govindaswami, S. 1967. Inheritance of grain size and its correlation with hulling and cooking quality. Oryza. 4: 12-21.

[17] Nanda, B. B., Ghose, A. K. andBehera, G. B. 1976. Variability in physico-chemical characteristics of somerice varieties. Riso (Italy). 25 (3): 265-270.

[18] Nirmala, B. 1997. Objective and subjective evaluation of foods. Lecture delivered to the participation of ICAR-Summer Course on "Under Food Grains: Quality Assessment, Technology for Use and Popularization". July 23 to August 1, 1997. College of Rural Home Science, UAS, Dharwad, Karnataka. Pp. 7.

[19] Osawa, T., Ramarathnam, N., Kawakishi, S. and Namiki, M. 1992. Antioxidative defense systems generated by phenolic plant constituents. ACS Symposium Series. 507: 122-134.

[20] Pandey, J. P. and Gupta, D. K. 2000. Interaction of physical and milling characteristics of paddy. Journal of Food Science and Technology. 37(2): 174-177.

[21] Prashant Ghadge, N. and Prasad, K. 2012. Some Physical Properties of Rice Kernels: Variety PR-106. Journal of Food Processing Technology. 3: 8 .

[22] Ramiah, K. 1993. Rice breeding and Genetics. Science Monograph. No. 19. Indian Council of Agricultural Research, New Delhi, Idia. Pp. 106. 
[23] Ravindra, V. Shreya, K., Kuldeep Singh Dangi and Nagesh. P. 2009. Evaluation of popular rice (Oryza sativa L.) Hybrids for Quantitative, Qualitative and Nutritional Aspects. International Journal of Scientific and Research Publications. 3 (1): 2250-3153.

[24] Reddy, G. S. 2000. Characterization and evaluation of the rice (Oryza sativa L.) cultivar Njavara M. Sc (Ag.) Thesis, Kerala Agricultural University, Thrissur. Pp. 137.

[25] Reddy, G. S. 2000. Characterization and evaluation of the rice (Oryza sativa L.) cultivar Njavara M. Sc (Ag.) Thesis, Kerala Agricultural University, Thrissur. Pp. 137.
[26] Srivastava, A. K., Jaiswal, H. K. 2013. Grain Characteristics and cooking quality of Indigenous Aromatic and NonAromatic Genotypes of Rice (Oryza sativa L.). International Journal of Scientific Research and Reviews. 2(1): 36-41.

[27] Thomas Rachel, Wan-Nadiah, W. A. and Rajeev Bhat. 2013. Physiochemical properties, proximate composition, and cooking qualities of locally grown and imported rice varieties marketed in Penang, Malaysia. International Food Research Journal 20(3): 1345-1351. 